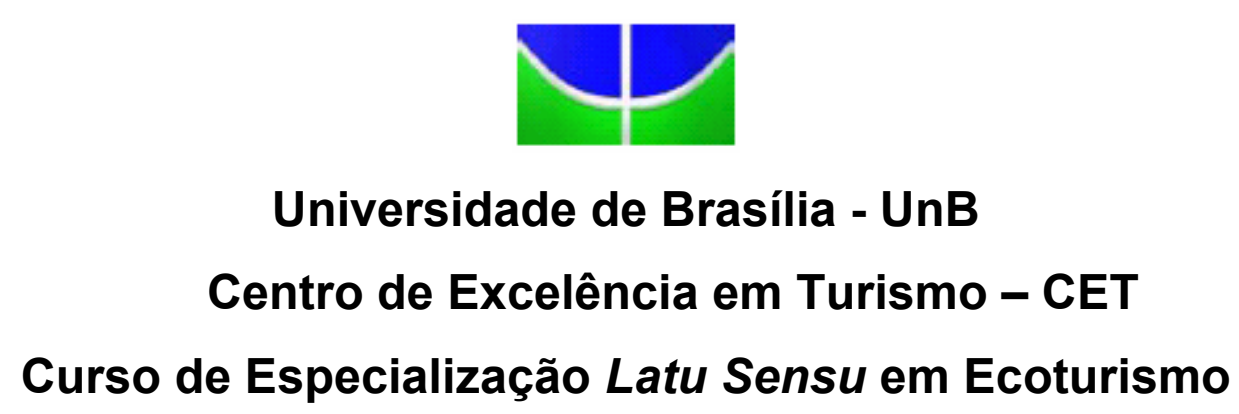

\title{
ECOTURISMO E SUSTENTABILIDADE CULTURAL: refazendo percursos
}

Anette Lobato Maia

Brasília, DF 


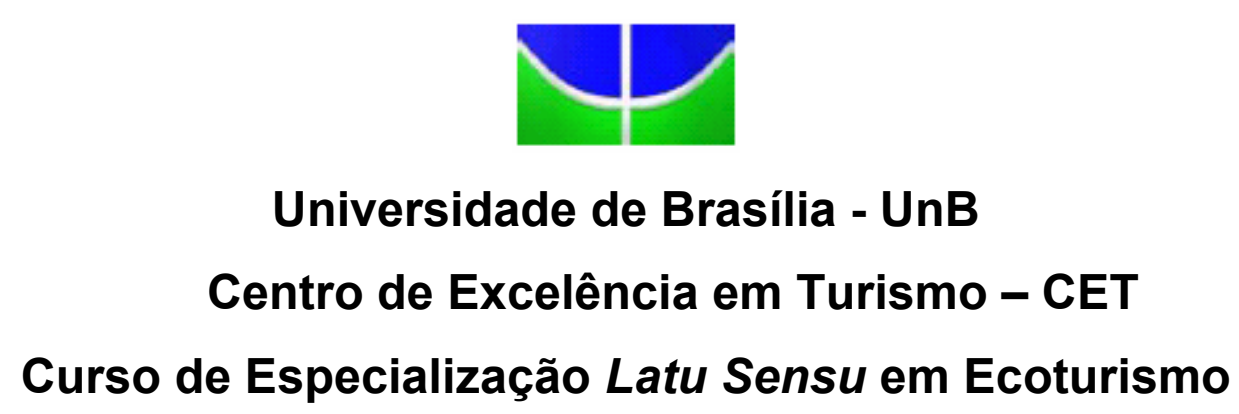

\section{ECOTURISMO E SUSTENTABILIDADE CULTURAL: refazendo percursos}

\section{Anette Lobato Maia}

Orientador: Manoel Cláudio da Silva Júnior

Monografia apresentada ao Centro de
Excelência em Turismo da Universidade de
Brasília como requisito parcial para obtenção
do certificado de Especialista em
Ecoturismo.

Brasília, DF

maio de 2003 
Maia, Anette Lobato

Ecoturismo e sustentabilidade cultural: refazendo percursos. / Anette Lobato Maia. - Brasília, 2003.

$49 \mathrm{f}$.

Monografia (especialização) - Universidade de Brasília, Centro de Excelência em Turismo, Curso de Especialização Latu Sensu em Ecoturismo, 2003.

Orientador: Manoel Cláudio da Silva Júnior.

I. Ecoturismo. II. Sustentabilidade cultural 


\author{
Universidade de Brasília - UnB \\ Centro de Excelência em Turismo - CET \\ Curso de Especialização Latu Sensu em Ecoturismo
}

\title{
ECOTURISMO E SUSTENTABILIDADE CULTURAL: refazendo percursos
}

Anette Lobato Maia

Banca Examinadora

Professor $\mathrm{X}$

Professor $Y$

Brasília, DF

maio de 2003 


\section{Agradecimentos}

Agradeço a todos que me inspiraram na execução desse trabalho, seja com uma visão otimista ou mesmo pessimista das coisas do mundo. Especialmente ao meu pai por ter sido um incentivador silencioso dessa jornada, à minha mãe por ter estado atenta e solidária nos momentos em que isso foi necessário e ao professor Manoel Cláudio por ter sido bastante presente na última etapa de redação dessa monografia. 
"Viajar sempre foi marca de distinção e poder".

Gustavo Lins Ribeiro, 1997 


\section{Resumo}

Pesquisa bibliográfica que reúne críticas que hoje se fazem ao Ecoturismo, tanto no aspecto teórico como prático, a partir de estudos no campo das Ciências Sociais e mais especificamente da Antropologia. Observou-se as relações estabelecidas entre os visitantes e os nativos, a percepção de natureza que possuem distintos setores afetos à atividade e a intervenção dos empreendedores de ecoturismo no fazer cultural das comunidades onde estão inseridos. Tomou-se como marco inicial do trabalho, a relação Ecoturismo - Desenvolvimento Sustentável, para depois se desenvolver o conteúdo relativo a sustentabilidade cultural. Apresenta ainda, sugestões levantadas a partir de leituras multidisciplinares, na expectativa de que possam reverter em resoluções para os problemas relativos a sustentabilidade cultural. 


\section{Abstract}

Extensive bibliografic research that present a great variety of argument related to Ecotourism. Studies were based on Social Sciences. Consideration was take on theorical and real life situations. Their themes were about the relation between natives and visitors, and the relation between Ecotourism and Culture. This monography also presents different suggestions, that could change some problems related to these diversified aspects of Ecotourism's activities. It is an expectative that one or more suggestions can be taken on consideration and used on the real world. 


\section{Sumário}

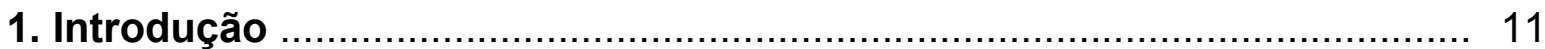

2. Breve Histórico do Ecoturismo …....................................................... 13

2.1 Ecoturismo no Brasil hoje ........................................................... 15



2.3 Análise de diferentes definições de ecoturismo ....................................... 16

2.4 Ecoturismo, desenvolvimento sustentável .......................................... 19

2.5 Ecoturismo e sustentabilidade cultural ................................................... 22

2.6 Apartação entre turistas e população visitada .......................................... 25

2.7 Produtos e turismo ............................................................................ 27

2.8 Ecoturismo e o discurso espetacular ............................................ 29

3. Descrição da pesquisa bibliográfica ........................................... 31

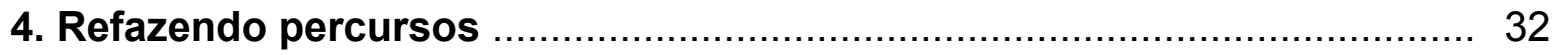

4.1 Plataformas de estudo do turismo ...................................................... 32

4.2 Polaridades da natureza humana ....................................................... 33

4.3 Levantando possibilidades de um turismo com sustentabilidade cultural ...... 36

4.3.1 Ecoturismo e turismo ............................................................................ 36

4.3.2 Visão edênica e apartação da natureza defensável ......................................... 37

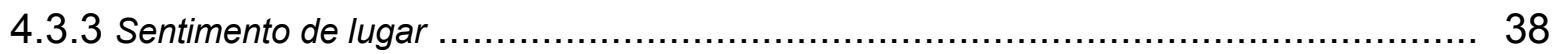

4.3.4 Ecoturismo, empreendedores e suas trajetórias .......................................... 40



Referências bibliográficas .................................................................. 46 


\section{Lista de abreviaturas}

ASPAC Associação de Silves pela Preservação Ambiental e Cultural

COOPTUR Cooperativa de Turismo em Silves -AM

EMBRATUR Instituto Brasileiro de Turismo

OCE Oficinas de Capacitação em Ecoturismo 


\section{Introdução}

Como forma de reatar o convívio com a natureza surgiu recentemente o ecoturismo, modalidade de viagem que já no nascedouro recebe críticas quanto a sua pretensa capacidade de se diferenciar do turismo de massa em relação aos impactos ambientais, sociais e culturais gerados por esse último.

As críticas estão situadas tanto no que diz respeito às diferentes definições de ecoturismo e seus significados, como também se encontram direcionadas aos aspectos teórico-práticos relativos a apartação entre turistas e nativos, à interferência dos empreendedores na cultura nativa e à visão espetacularizada de natureza que agentes governamentais, do trade ecoturístico e de ONG's veiculam via imagens ou discursos. Ressalte-se que essas visões não condizem com uma modalidade de turismo que se pretende sustentável no plano da cultura das comunidades visitadas.

Assim, o objetivo desse trabalho visa reunir e analisar através de pesquisa bibliográfica, práticas cotidianas e concepções que atentam contra a sustentabilidade cultural no campo do ecoturismo, com o intuito de apontar sugestões que mitiguem ou sanem as distorções evidenciadas, reforçando com as citadas medidas os princípios e critérios para o exercício do ecoturismo formulados pelas Oficinas de Capacitação em Ecoturismo realizadas em 1994, as quais são apresentadas a seguir.

\section{Princípios do Ecoturismo:}

- Conservação e uso sustentável dos recursos naturais e culturais;

- Informação e interpretação ambiental;

- Deve haver reversão dos benefícios para a comunidade local e para a conservação dos recursos naturais e culturais;

- Deve ter envolvimento da comunidade local. 


\section{Critérios do Ecoturismo:}

- Manejo e administração verde do empreendimento;

- Associações e parcerias entre os setores governamentais e não governamentais locais;

- Educação Ambiental para o turista e comunidade local;

- Guias conscientes, interessados e responsáveis;

- Planejamento integrado, com preferência à regionalização;

- Promoção de experiências únicas e inesquecíveis em um destino exótico;

A importância de se abordar tal tema reside na necessidade de se promover efetivamente a sustentabilidade cultural no ecoturismo, de se romper com práticas que aviltam ou ameaçam aviltar às populações receptoras que muitas vezes se tornam mais vítimas desse empreendimento que beneficiárias, em razão dos impactos negativos gerados pela quebra de tradições e pela apartação do convívio mais humanizado, quando a atividade não é planejada dentro das seis dimensões sustentáveis: a econômica, a ecológica, a político-institucional, a cultural, a social e a espacial. Impactos negativos se revelam na perda de identidade dessas populações, fato que se materializa na quebra de suas tradições e no rompimento dos elos que mantêm seus indivíduos coesos.

O turismo feito sem princípios e critérios não abala somente a fauna, a flora, os rios e o ar, mas também as populações nativas que se desagregam e se tornam vítimas de uma economia, que deveria beneficiá-las prioritariamente. A cultura de cada povo que acolhe turistas em suas localidades de residência deve ser também objeto de cuidados e de respeito por parte dos empreendedores e não tão somente os aspectos biofísicos da localidade.

A sustentabilidade cultural aqui reivindicada ultrapassa a tomada de cuidados com as tradições, com a religiosidade e com as festividades das populações visitadas. Ela almeja mais, tendo como intuito o encontro entre visitantes e nativos, a fim de que transcendam ao mero respeito distanciado, revelando a possibilidade de 
convivência, de troca e de partilha entre seres humanos por mais diferentes que sejam, por mais breve que seja a estada do viajante.

O trabalho está estruturado de forma a levar a orientar no entendimento dos elementos que levem a reflexão sobre os impactos do ecoturismo, tal qual este está inserido na vida das sociedades, tendo a seguinte apresentação:

Capítulo 2 - Apresenta um breve histórico de Ecoturismo, para em seguida abordar diferentes definições de Ecoturismo, procedendo às análises do mesmo. Em seguida, há uma análise sobre o conceito de Desenvolvimento Sustentável e sua relação com o Ecoturismo. Por último, faz-se uma análise da dimensão da sustentabilidade cultural na atividade ecoturística e aborda práticas e concepções que ameaçam a sustentabilidade cultural no Ecoturismo.

Capítulo 3 - Descreve como foi feita a pesquisa bibliográfica para a monografia.

Capítulo 4 - Situa os diferentes momentos da pesquisa científica em turismo. Aborda também um estudo de Boff sobre a polaridade da natureza humana e a partir do mesmo aponta possibilidades para corrigir distorções evidenciadas.

Capítulo 5 - Faz as considerações finais, fazendo as análises e conclusões acerca do tema estudado.

\section{Breve histórico do Ecoturismo}

O termo ecoturismo surge ao final da década de 70 e início da década de 80 do século passado, em um contexto de transição, onde segmentos das sociedades pós-industriais repensam suas formas de lazer, questionam as formas brutais de sua inserção dentro do sistema produtivo e econômico e, de alguma forma, perseguem o elo perdido no processo civilizatório (nos períodos de férias e feriados prolongados), na oportunidade do encontro com a natureza em estado não degradado. 
O surgimento do ecoturismo no Brasil está relacionado aos vínculos entre turismo e ambientalismo. Conforme Pires (1998, pp. 206-207) apud Gomes (2000) o ecoturismo surge no país a partir de três vertentes, que vieram a caracterizar seus futuros estilos:

- a da experiência hippie, de cunho contemplativo;

- a de estudos do ambiente de aspecto interpretativo e educativo; e

- a do excursionismo, que levou ao aspecto mais aventureiro da atividade.

Essas modalidades surgiram exatamente durante a ascensão do movimento ambientalista (a partir de 1970) o qual deu visibilidade aos impactos negativos ocasionados pela industrialização e também aos efeitos maléficos ocasionados pelo turismo de massa.

No decorrer da história recente do turismo, o ecoturismo surge e se impõe como um "emblema " utilizado para representar um conjunto bem variado e não bem definido de atividades e atitudes no campo da viagem turística. (Gomes, 2000, pg 48).

O ecoturismo está ligado historicamente ao renascimento da sensibilidade ecológica oriunda da luta ambientalista deflagrada nos últimos 30 anos, sendo influenciado por muitas idéias e debates que o ambientalismo vem colocando em pauta no decorrer deste tempo, como por exemplo, a idéia de desenvolvimento sustentável.

Ressalta-se que antes de se denominar ecoturismo às viagens de perfil degradatório, já havia pelos idos de 1970 a promoção de viagens que evitavam repetir os efeitos do turismo de massa chamados de 'turismo de natureza' e ' de descoberta' entre outras denominações. Em razão de o termo Ecoturismo carregarse da mensagem conservacionista, o mesmo passou a se tornar à denominação hegemônica após 1990, tendo as demais terminologias caído em desuso ou tratadas como sinônimo do mesmo, ainda que por vezes, de forma inadequada. 


\subsection{Ecoturismo no Brasil hoje}

Salvatti (2002, p. 13) coloca que grande parte do turismo realizado na atualidade no Brasil é feito em áreas naturais, citando que o Instituto de Ecoturismo no Brasil contabiliza no país meio milhão de pessoas praticando turismo nessas áreas na figura de turistas, ainda que não se esteja em todos os casos, praticandose efetivamente o Ecoturismo na acepção das OCE.

Salvatti (2000, p. 13) pesquisou dados do ano de 2000 fornecidos pelo Ministério do Meio Ambiente e Conservation International que contabilizaram no Brasil mais de 25 publicações periódicas de turismo e meio-ambiente, a existência de 1600 ecolodges (refúgios de selva), além de 300 agências e operadoras comercializando produtos de ecoturismo. O mercado ecoturístico tende a crescer cada vez mais tendo em vista a divulgada megadiversidade brasileira e a necessidade que o país tem de criar divisas internacionais, situação essa partilhada por alguns países de Terceiro Mundo, também megadiversos como Costa Rica, África do Sul, Quênia, dentre outros.

\subsection{Polissemia de ecoturismo}

O significado do termo Ecoturismo (ou Turismo Ecológico) vem sendo construído de forma polissêmica, abarcando um sem-número de sentidos, uns bastante claros e outros repletos de lacunas, imprecisões ou insuficiências. Além disso, é confundido com modalidades de turismo feito em cenários naturais, mas que não se apóiam em compromissos com qualquer tipo de sustentabilidade. São apenas modalidades de turismo na natureza.

Ceballos-Lascuráin (1996) é tido como provável criador do termo Ecoturismo e assim o define em tradução de Pires (1998, p. 190)

Ecoturismo ou turismo ecológico consiste em viagens ambientalmente responsáveis com visitas a áreas naturais 
relativamente sem distúrbios, para desfrutar e apreciar a natureza-juntamente com as manifestações do passado ou do presente que possam existir, e que ao mesmo tempo promove a conservação, proporciona baixo impacto pelos visitantes e contribui positivamente ao envolvimento sócio-econômico ativo das populações locais. (Ceballos-Lascuráin apud Pires, 1998).

\title{
2.3 Análise de diferentes definições de ecoturismo
}

\author{
De acordo com a Embratur (1994):
}

"ecoturismo é um segmento da atividade turística que utiliza, de forma sustentável, o patrimônio natural e cultural, incentiva a sua conservação e busca a formação de uma consciência ambiental através da interpretação do ambiente, promovendo o bem-estar das populações envolvidas" (Embratur, 1994).

Coriolano (2000, p. 12) define ecoturismo como a viagem que conjuga os princípios da ecologia com os princípios do turismo. Assim, "a essência do turismo é o entretenimento ou o lazer e a essência da ecologia é a conservação ambiental".

Swarbrooke (2000) afirma que o termo ecoturismo é de difícil definição porque cada sujeito envolvido na prestação do serviço tem uma visão diferente do que ele venha a ser.

"Para o turista, o ecoturismo é sinônimo de férias modernas, que podem conferir um status elevado a seus praticantes; é freqüentemente identificado com turismo de qualidade. Para a indústria, o ecoturismo é um produto que oferece margens de lucro atraentes e dispõe de um mercado extenso e em expansão. Já para as destinações que têm emergido ultimamente, o ecoturismo é altamente rentável, representando um turismo de volume pequeno que permite diferenciá-lo da concorrência". (Swarbrooke, 2000) 
No entanto, os formadores do trade ecoturístico assim o definem:

"O ecoturismo é toda atividade turística realizada em área natural com o objetivo de observação e conhecimento da flora, da fauna e dos aspectos cênicos (com ou sem o sentido de aventura); prática de esportes e realização de pesquisas científicas”. (Ruschel apud Serrano, 1997)

Por sua vez, Gomes (2000), coloca que:

“...o ecoturismo poderia assumir um outro significado, ser uma atividade que privilegia o encontro, em vista dele suscitar outras possibilidades nas relação dos homens e das mulheres entre si e destes com a natureza, desde que os ecoturistas estejam em busca de modificar o seu cotidiano e não fugir dele, e que os nativos se mostrem contra a invasão e sua exclusão do processo, inaugurando a possibilidade de dialogo entre visitantes e anfitriões". (Gomes, 2000, p. 59)

É notável a diferença de perspectiva com relação ao ecoturismo nas definições da Embratur (1994) e Coriolano (2003) e depois, nas apresentadas por Swarbrooke (2000) e pelo trade do ecoturismo. A última definição dista em maior grau das demais por ter um caráter mais filosófico e transcendente. Cada uma delas, portanto, acarreta implicações diferenciadas. Enquanto a Embratur (1994) emprega termos como 'utilização sustentável' e 'conservação', Coriolano (2003) por sua vez, recorre aos termos ecologia e também conservação, sendo que as duas últimas são mais pragmáticas. Estão mais atentas a um mercado de contemplação que cresce mundialmente e aos ganhos financeiros que isso representa.

Ainda que a Embratur (1994) não consiga dar na prática conseqüência à definição que assume para si, pelo menos ela está na órbita onde circula o pensamento (acadêmico ou não) daqueles que almejam formas de desenvolvimento não aniquiladoras da natureza. 
Coriolano (2003) aprofunda mais sua visão do tema prescrevendo que o ecoturismo deve conservar e preservar conforme a situação apresentada, distingüindo os locais de pura contemplação e aqueles onde está assegurada à presença humana com intervenções programadas.

A autora acredita que o ecoturismo deva estar inserido em um projeto de desenvolvimento sustentável. Ela percebe, no entanto, que no mundo do trade os termos 'sustentabilidade' e 'desenvolvimento sustentável' não são termos inerentes à construção do ecoturismo.

Swarbrooke (2000) é bastante claro. Tem como aspiração para o Ecoturismo um futuro compromisso com a sustentabilidade, mas sabe que para isso se torne exeqüível, a atividade terá que transcender à mera contemplação e seus empreendedores por outro lado romper com o trato exclusivamente comercial dos seus serviços. Daí a razão para o autor separar didaticamente turismo sustentável de ecoturismo, almejando que o último venha a ser, no futuro, o que definiu como Ecoturismo Sustentável.

A definição do trade é pragmática por outros motivos. Vendo a natureza como um grande produto a ser comercializado, só cabe falar de sustentabilidade quando isso se relacionar imediatamente com lucros, caso contrário, a preocupação com a mesma não tem a relevância para ser citada como prioridade a ser gerida pelo setor. Até porque assumir compromissos dessa natureza (e a priori) significa impactar lucros advindos de sub-produtos da viagem e que, sendo deixados de produzir, acabam por ferir inúmeros interesses e interessados.

A última definição está em um campo que reivindica o não-consumismo e maiores valores de transcendência durante a viagem, distanciando-se mais dos conceitos do trade e de Swarbrooke (2000) e menos dos de Coriolano (2003) e EMBRATUR (1994), embora os pesos economicista e tecnocrático de ambos sejam fortes. 


\title{
2.4 Ecoturismo e desenvolvimento sustentável
}

Para dar início à discussão, Desenvolvimento Sustentável hoje pode ser definido entre outras possibilidades como:

\begin{abstract}
"O desenvolvimento baseado no uso produtivo de recursos naturais para o crescimento econômico e fortalecimento dos meios de vida, que conserva simultaneamente a diversidade biológica e social que constituem parte integrante desse processo". (Hall, 1997, p. 273)
\end{abstract}

A denominação Desenvolvimento Sustentável foi primeiramente utilizada com caráter oficial como política mundial no Relatório Brundtland em 1987, quando as Nações Unidas elaboraram este último com o intuito de dar uma resposta mundial à luta ambientalista que se deflagrava contra a crise ecológica em vários países de economia central.

Quando diferentes autores querem aliar o ecoturismo ao corpo teórico do Desenvolvimento Sustentável, parece se estar falando de algo consensual. De um corpo monolítico por onde não pairam divergências, o que é uma visão equivocada:

"A determinação do sentido de Desenvolvimento Sustentável é subordinada ao perfil político-ideológico dos diferentes agentes sociais e á própria forma como cada um destes constrói sua concepção de meio-ambiente". (Ribeiro; Barros, 1997, p. 40)

A discussão sobre Ecoturismo e Desenvolvimento Sustentável, portanto, não escapa de um confronto ideológico, ideologia aqui entendida como um conjunto coerente de imagens, idéias e valores compartilhados culturalmente (Pareschi, 1997) e que varia, portanto, entre grupos.

Lunas (2000), por exemplo, entende que: 
"A preocupação com o desenvolvimento sustentável das novas

e futuras gerações representa uma oportunidade para o

Ecoturismo que pode explorar o aumento da consciência ambiental na adaptação, na comunicação e na avaliação de seu produto turístico". (Lunas, 2000, p. 97)

Mas há quem discorde com veemência da possibilidade de o Desenvolvimento Sustentável sequer existir, quanto mais ser associado ao Ecoturismo. E esse dissenso quanto a um assunto aparentemente consensual é apresentado por Rodrigues (2000). A autora menciona uma contradição entre os termos desenvolvimento e sustentabilidade, assim explicada:

Desenvolver - implica na produção de mais e mais mercadorias, gerando extração de recursos, além da criação de resíduos, muitos sem depósitos existentes para alocá-los.

Sustentabilidade - significa manutenção das condições anteriores à produção.

Como o desenvolvimento se faz de forma contínua, a autora o coloca como insustentável "tanto pela rapidez com que os processos produtivos têm se transformado, como pela forma como a natureza vem sendo encarada: como uma nova mercadoria. O uso intensivo dos ecossistemas tem esgotado rapidamente os chamados recursos naturais e sua capacidade de recomposição". (Rodrigues, 2000, p. 177).

Em sua compreensão o termo sustentabilidade passa a não ter sentido, por não haver viabilidade de se manterem as condições anteriores à produção, pois, esta não cessa nunca. Assim ela sentencia: "a atividade turística é em sua essência incompatível com a idéia de desenvolvimento sustentável".

Rodrigues (2000) considera que a mesma vive da utilização fugaz da natureza via consumo de paisagens e da criação ostensiva de produtos a partir dela. Para a autora, o turismo sequer é auto-sustentável face ao disposto. A reflexão é de 
que ao mesmo tempo em que a natureza é um palco sagrado em algumas construções, ela também é mercadoria submetida a todos os ditames comerciais. É como se fosse o Reino vigiado por vendilhões.

No pensamento de Ribeiro (1992), a avaliação de que o Desenvolvimento Sustentável pode ser uma alternativa às formas históricas do desenvolvimento advém da crença de que se compatibilizando interesses a principio antagônicos (lucro e preservação da natureza) e dominando o funcionamento e articulação de diferentes agentes econômicos, através de minuciosas ações de planejamento, ele venha a se tornar realidade. O que ele estranha é que sequer é mencionada nesse modelo a exploração de uns setores sociais por outros. O que o torna limitado, insuficiente, mas não ingênuo.

Esta insuficiência não é gratuita. Quem tenta percorrer a árvore genealógica do Desenvolvimento Sustentável vai achar seus ascendentes no projeto desenvolvimentista de marca liberal voltado para o meio-ambiente. Este tinha como intuito assegurar uma gestão ambiental dentro de um projeto de desenvolvimento onde o patrimônio natural também passa a ser mais um bem dentro da perspectiva produtivista conforme descreve Carvalho apud Ribeiro (1992). O marco iniciador dessa tendência é a Conferência de Estocolmo em 1972, evento que teve influência nessa conceituação por conseguir articular termos como desenvolvimento sustentável, o bem estar-social e crescimento econômico de forma bastante positiva e convincente, tornando-o popular e aclamado.

Da forma como se engendrou o conceito e seus derivados mais semelhantes, o Desenvolvimento Sustentável passou a ser usado como um instrumento que confere brio a proposições nem sempre revestido de dignidade, pois o conceito parece conseguir dar um lustro mesmo às intenções mais foscas.

Em razão dessa diferenças Gomes (2000) situa dois campos de entendimento do Ecoturismo no tocante ao item que aqui se desenvolve: 
“....o 'Desenvolvimento Sustentável' é visto como idéia reguladora de Ecoturismo. Em face da existência do domínio da abordagem "técnica", o significado do Ecoturismo assume um viés com predominância no econômico, cujo discurso enfatizará o caráter da viagem demandada por estilo de vida sofisticado, o alcance do "desenvolvimento sustentável" e, portanto, da 'conservação do patrimônio natural', da geração de emprego e renda, situação que podem confluir os interesses da maioria dos agentes intervenientes na atividade. Em contrapartida, identificase, no campo da disputa em torno do significado do ecoturismo, as posições que pleiteiam uma nova ética na viagem, que fundada nas experiências mais profundas, fossem estimuladoras de uma consciência ambientalista de recusa dos valores materialistas da sociedade de consumo, além de possibilitar o encontro entre ecoturistas e anfitriões". (Gomes, 2000, p. 56)

Resumindo, no ecoturismo as terminologias uso sustentável e Desenvolvimento Sustentável são aceitas no discurso oficial (interessante seria um futuro estudo sobre a recente implantação do turismo dentro das reservas extrativistas, posto que se apóiam nesse conceito), no discurso de ONG's e até eventualmente, no privado. Porém, seus conteúdos e possibilidades são objetos de controvérsia constante. Uns aceitam o conceito mesmo com suas limitações e imprecisões e tentam aplicá-lo com ou sem reelaborações, no cotidiano da atividade ecoturística e outros, o questionam a ponto de rechaçá-lo completamente como alternativa ao atual modelo de desenvolvimento.

\subsection{Ecoturismo e Sustentabilidade Cultural}

Centenas de conceituações de diferentes matizes ideológicos gravitam em torno da popularização do conceito de desenvolvimento sustentável, inscrito no Relatório Brundtland, na base a tríade sustentabilidade econômica, social e ecológica, solidária com as gerações vindouras, conforme Bezerra (2000, p. 51).

O esforço em se fazer do ecoturismo um projeto sustentável deve direcionarse às sustentabilidades econômica, social e ecológica e ampliar-se para outras três 
dimensões abordadas por Bezerra e Bursztyn, (2000, p. 51) além das já citadas. Ambos inspirados no trabalho sobre ecodesenvolvimento de Sachs (1993) apresentam as seguintes dimensões:

- sustentabilidade social - ancora-se na eqüidade de distribuição de renda e de bens, baseada na igualdade de direitos à dignidade e no princípio de solidariedade dos laços sociais;

- sustentabilidade ecológica - baseia-se no princípio de solidariedade com o planeta e a biosfera;

- sustentabilidade econômica - avaliada partindo da sustentabilidade social alcançada através da organização da vida na esfera material;

- sustentabilidade espacial - norteada pela conquista de equanimidade nas relações inter-regionais e na distribuição populacional entre o meio rural e urbano;

- sustentabilidade político-institucional - vista como pressuposto para a continuidade de ações que sejam desenvolvidas em longo prazo; e,

- sustentabilidade cultural - baseada no respeito à afirmação dos âmbitos local, regional e nacional frente a padronização imposta pela globalização e que vem a ser foco de maior interesse no desenvolvimento deste trabalho.

Bezerra(2000) e Bursztyn (2000) afirmam que o desafio dos projetos sociais de desenvolvimento sustentável devem se debruçar prioritariamente sobre as identidades sociais, regionais e étnicas existentes em diferentes sociedades para se direcionarem, depois, aos aspectos econômicos e geopolíticos.

Se o ecoturismo reivindica os princípios e critérios adotados pela OCE, ele está em perfeita sintonia com o conteúdo da sustentabilidade cultural e com a necessidade de vê-la como instrumento de afirmação de identidades. O exercício da sustentabilidade cultural pelo ecoturismo é tarefa inadiável em um mundo em que o liberalismo de mercado não valoriza as tradições e raízes dos diferentes povos. $\mathrm{O}$ liberalismo precisa uniformizar a humanidade para ser hegemônico economicamente e esse pressuposto é incompatível com o ecoturismo. 
Mesmo o periódico econômico Financial Times reconhece que o domínio hegemônico da restritividade da lógica econômica incide diretamente nos critérios de produção em massa de bens intelectuais, nos julgamentos e nas opiniões, conforme demonstrado por Bezerra e Bursztyn (2000).

A sustentabilidade cultural não pode ser vista como um adereço pelos que trabalham com a atividade ecoturística em seus diferentes níveis, no planejamento e/ou execução, sob risco de servir a um modelo econômico que nada tem a ver com o desenvolvimento sustentável e nem com a solidariedade entre os povos e seu direito de existir com diferentes culturas, credos, valores. A sustentabilidade do ecoturismo não é uma questão relativa somente aos aspectos biológicos e físicos da natureza ou aos econômicos da atividade. A sustentabilidade deve ser buscada no plano humano, na valorização de cada cultura que é a manifestação concreta de como cada povo ou grupo humano, dentro de sua própria lógica, articulou seus recursos para sobreviver frente a todas as intempéries. Cultura é riqueza e cada povo tem sua riqueza singular engendrada diante das facilidades ou dificuldades oferecidas pelo meio em que vive.

A viagem ecoturística tem um enorme potencial de fazer da sustentabilidade cultural uma marca que influencie e inspire até outras atividades econômicas na medida em que turistas e população receptora tenham um encontro verdadeiro, produto de um planejamento que contemple a conversa, a discussão sobre o modus vivendi de cada um buscando entenderem-se na diversidade e na construção de tolerâncias.

Sem a sustentabilidade cultural qualquer iniciativa de sustentabilidade é inócua, pois povos aviltados, sem auto-estima, sem cultura a defender não podem ter condições de lutar por qualquer coisa que não seja a sobrevivência imediata. 


\subsection{Apartação entre turistas e população visitada}

O perfil sócio-econômico do ecoturista é elevado, bem acima da média da sociedade brasileira. Segundo Azevedo (2003) trata-se de cidadãos com experiência em viagens internacionais, com idade entre 33 a 55 anos, apreciadores do exótico, da fauna e da flora preservados, em suma, de gente preocupada com o meio ambiente, não deixando de frisar que preocupado não quer dizer militante, ambientalista e entendedor dos itens que levam a sustentabilidade. Trata-se de um público atento às novidades no setor, buscando produtos novos continuamente. Por isso é temível que a disputa por clientes possa levar os empreendedores a abrirem mão dos princípios e critérios do Ecoturismo.

Dentre 15 lodges pesquisados por Azevedo (2003) na região Amazônica, apenas um foi identificado como realizador de Ecoturismo Comunitário, envolvendo manejo sustentável, o que caracteriza os empreendimentos da região visitada como propiciadores de turismo na natureza (alguns com muito luxo e conforto) e não como ecoturísticos.

\footnotetext{
"Muitas vezes os turistas acabam comprando pacotes com algum rótulo de 'eco' e julgam estar dando uma contribuição à natureza. No caso do turismo desenvolvido pelos lodges (exceção feita a Pousada Aldeia dos Lagos) no Amazonas, após várias visitas e através da observação participante, observou-se o uso do turismo de natureza e não do ecoturismo." (Azevedo, 2003)
}

Conclui-se que o ecoturismo nesses e em outros lodges é um processo equivocado, apesar de caro. Por isso há autores que acreditam que o verdadeiro turismo poupador da natureza é o realizado em Colônias de Férias do SESC e do Banco do Brasil, porque os equipamentos que elas utilizam são bem mais socializados. O que é uma polêmica e tanto para quem conhece esses empreendimentos hoje. Para Yázigi (1999, p. 129) essas colônias "representam o futuro mais acertado do turismo e conseqüentemente de preservação da natureza". 
As críticas a empreendimentos concebidos da forma dos lodges anteriormente citados não param por aí. Se a base comunitária do Ecoturismo não é feita, o turista vê de tudo um pouco (animais, plantas, cachoeiras) menos a relação que os seres humanos que vivem no local estabelecem com a natureza e com a vida e que se diferencia bastante de povo a povo. O lamentável é que, muitas vezes, o turista se fecha, entre seus semelhantes, nos lodges e de lá retorna para casa com a visão superficial (centrada nos valores de sua cultura) de que os nativos, "são pobres, mas felizes. Despreocupados e hospitaleiros. Mas naturalmente, um tanto desorganizados, não muito limpos, pode-se até dizer que sujos, mas de qualquer forma, extravagantes, preguiçosos e pouco inteligentes” (Krippendorf, 2001, p. 87).

Embora os resultados da pesquisa realizada por Azevedo (2003) não devam ser objeto de generalização do quadro de sustentabilidade para todo o Brasil, é preciso que se trabalhe junto aos empreendedores e profissionais de turismo a valorização dos aspectos de convívio entre turistas e população receptora. Um turismo que distancie visitantes e visitados não desperta para aceitar o nativo dentro de seus costumes, valores, paixões e simbolismos. Assim, aprofunda apartações, intolerâncias, e transforma os lodges em bem montados e auto-suficientes guetos verdes, onde o contato com o diferente é fugaz (e não estimulado), em nome da tranqüilidade e paz necessárias para contemplar a natureza.

O impacto negativo que questões como essa geram são enormes e se para os nativos for muito perceptível essa separação, um dos efeitos pode ser 0 aparecimento de "ressentimentos diante de hábitos e comportamentos de turistas e da ostentação de tempo e dinheiro, muitas vezes escassos para os moradores das localidades”. (Ruschmann, 1999, p. 64).

Acaba-se por concluir que aos turistas mais atentos e cuidadosos cabe solicitar aos empreendedores visitas mais amplas, que incluam a possibilidade de enxergar a natureza vendo o homem dentro dela, até para que se possa ter uma relativização frente aos valores assumidos por suas próprias culturas, propiciando ao nativo, por sua vez, a experiência de vivenciar uma relação mais positiva com o visitante. 


\subsection{Produtos e turismo}

A questão do respeito às culturas receptoras é abrangente. Vale no que se referem às suas crenças, valores e costumes, como também ao direito de manterem preservadas as suas manifestações artísticas e culturais.

Infelizmente não são poucos os empreendedores que tentam dar um "acabamento" mais vendável aos artefatos produzidos por populações em zonas turísticas.

Não conseguem entender que um vaso de cerâmica, uma boneca de pano, um instrumento musical são produtos de uma elaboração por vezes antiga, e que envolve sentimentalidades, concepções de mundo, religiosidades que sofrendo intervenções brutais de uma estética comercial, quebram elementos que fazem uma determinada cultura coesa e diferente.

O mesmo procedimento acaba por se repetir nas festividades que as populações nativas realizam. O exemplo estudado no Pará é emblemático, mesmo se tratando de um turismo ecológico:

“...podemos perceber algumas modificações com o carimbó em Soure: ele agora já não é dançado nas festas da comunidade, e sim realizado nos salões dos hotéis ou em festivais programados; o lazer do 'caboclo' já é agora trabalho, pois dança para ganhar dinheiro (cada apresentação é paga); o ritmo torna-se rápido; os turistas são chamados a participar; enfim, o que antes era lazer, dançado em todas as festas, transforma-se em espetáculo, em que cada apresentação precisa de uma 'produção' ainda que pequena". (Figueiredo, 2001, p. 219)

Longe de se pensar que se pode congelar uma cultura qualquer, protegendoa de contatos externos para que se mantenha "pura" e sem modificações, a questão agora colocada é pensar até que ponto as populações de áreas ecoturísticas estão 
tendo condições de debater os imperativos de um turismo, que mesmo tendo o prefixo eco, pode ameaçá-las sutilmente, dia-a-dia. Até que ponto as intervenções das comunidades estão embasadas para uma discussão que evite seu estrangulamento cultural? Será que os muitos ambientalistas e demais especialistas que lhes dão assessoria possuem um olhar voltado para a cultura como elemento de coesão comunitária e que pequenas rupturas, aqui e ali podem ser letais? Em que medida a modificação no modus operandi de um determinado artefato ou festividade é produto de pressões do mercado ou é produto de intercâmbios culturais ou mesmo fruto de uma pensada e repensada negociação?

Para Figueiredo (2001) "a participação popular na hora do planejamento turístico deve também atentar para o aspecto da cultura, que corresponde a um dos principais apelos ao lado da natureza, para o Turismo Ecológico” (Figueiredo, 2001, p. 220).

Esse cuidado ao planejar confere a coesão dos diferentes elementos que compõem uma cultura, não permitindo que ela se rompa e que o grupo em que ela se insere tenha a sua identidade ameaçada. A manutenção da sustentabilidade cultural se faz tendo cuidado com quaisquer manifestações culturais do povo visitado, ainda que não seja compreendida por todos os visitantes que a ela tenham acesso.

$\mathrm{Na}$ pesquisa de Azevedo (2003), o empreendimento Aldeia dos Lagos (Silves/AM) foi a única experiência considerada sustentável entre 15 lodges pesquisados, como já foi dito. O diferencial apresentado pela investigadora está na contemplação de dois itens:

a) Os roteiros incluem uma aproximação mais profunda com o 'saber tradicional' e a 'experiência' das populações tradicionais e,

b) A natureza é de uso social, sendo que o turismo é vivido no dia-a-dia dos ribeirinhos, com suas tradições culturais. 
A autora esclareceu também que o empreendimento é gerido pela COOPTUR (Cooperativa de Turismo) e pela ASPAC (Associação de Silves pela Preservação Ambiental e Cultural). Acrescentou que o principal gestor da Aldeia dos Lagos entende que o ecoturismo é "uma alternativa a mais e que não irá suprir as outras alternativas já desenvolvidas pelas comunidades". Ao contrário, ele pensa que a pesca e o artesanato aliados ao ecoturismo trarão mais envolvimento dos ribeirinhos com o projeto. Essa é uma experiência de lodge onde se abrigam no máximo 24 hóspedes.

As 22 comunidades envolvidas com o ecoturismo em suas imediações acreditam que o "verde vende". Mas Azevedo (2003) faz a ressalva de que as experiências vividas procuram ser ecologicamente corretas, buscando a harmonia entre o turismo sustentável e o lucro. Combinação que ser questionada por alguns autores, mas que está em sintonia com os debates e reformulações feitos por diferentes setores do ambientalismo a partir do surgimento da idéia de Desenvolvimento Sustentável em 1972 em Estocolmo, merecendo assim, maiores cuidados por parte de pesquisadores de diferentes áreas.

\subsection{Ecoturismo e o discurso espetacular}

Gomes (2000) ao analisar os discursos proferidos pelo Ecoturismo a respeito das paisagens e da natureza propriamente dita, identifica uma retórica básica de quem lida com o empreendimento. "Santuário Ecológico", "refúgio de vida silvestre", "natureza virgem ou mesmo intocada", são expressões que povoam o falar de um campo que ele distinguiu como comunidade ecoturística. Dentro desse campo se situam ONG's ambientalistas, que em seu estudo apresentam-se como possuidoras de um saber mais especializado para desenvolver o Ecoturismo, pois têm um domínio técnico maior da atividade e de seus pressupostos. O Estado em menor grau também possui quadros para uma formulação desse tipo. Só não possuem os quadros com maior grau de elaboração os operadores do trade, embora os mesmos se sirvam das mesmas expressões que já foram citadas no tocante a natureza. 
Porém "o fato de seu exercício ecoturístico orientar-se pela idéia do lucro, não as torna tão vinculadas com o ideário ambientalista”. (Gomes, 2000).

Para o autor, no ecoturismo a natureza é espetacularizada (conduta profundamente arraigada na cultura contemporânea ocidental), associada a uma vida selvagem, distanciada da civilização corruptora. As expressões do discurso do espetáculo se tornam maiores nas mensagens das operadoras, mais brandas nos das ONG's e menores na retórica do Estado.

O interessante é que as ONG's por mais tecnicamente dotadas que sejam, embora não tendam a espetacularizar a natureza, não escapam à tentação de estetizá-la, pois os locais onde sediam suas ações, pelo menos no Brasil, estão dentro de um mesmo perfil turístico, a exemplo de locais como a Amazônia, Chapada dos Veadeiros e Fernando de Noronha.

Esse tipo de intervenção não é educativa e causa interpretações danosas a natureza podendo alterar também a forma como as populações afastadas dos grandes centros urbanos a percebem. $O$ homem urbano contemporâneo vive a sociedade do espetáculo conforme Debord (1997), consumindo o belo, o efêmero e o descartável, até que apareça algo melhor com as mesmas características. Ele quer viajar para ver um cenário espetacular, porém nenhuma área natural está livre de intempéries. A seca e o fogo nas matas do cerrado mancham o imaginário edênico da Chapada dos Veadeiros, por exemplo. A sua visita pode ser cancelada por esse motivo. Porém se as populações locais aprenderem a valorizar o local somente em função de suas belezas, o que fará durante e após uma grande catástrofe ambiental? Abandonará o local que seus antepassados souberam cuidar apesar das adversidades? Buscará outros lugares espetaculares para viver? Tanto os discursos oficiais, quanto os das ONG's e empreendedores formarão opinião inconteste senão houver oposição a essa mentalidade consumista urbana transposta para o Ecoturismo. 


\section{Descrição da pesquisa bibliográfica}

Em razão de haver a percepção de que os profissionais de ecoturismo não tinham como tema de debate os impactos culturais da atividade, embora dessem destaque forte aos impactos ecológicos, a necessidade de estudar melhor as questões relativas à sustentabilidade cultural se fez presente. A primeira descoberta foi de que existem poucas publicações sobre o assunto, mesmo diante desse quadro insistiu-se em buscar os poucos artigos disponíveis com a expectativa que revelassem algumas experiências abordando o universo de quem está envolvido com Ecoturismo, a fim de perceber como se dá a ameaça à sustentabilidade cultural, descobrir os agentes promotores da ameaça e colher nas publicações possíveis soluções.

Dos diferentes artigos colheu-se três situações ou exemplos emblemáticos de trajetórias distorcidas do Ecoturismo e a partir deles se procedeu à análise de cada problema detectado, verificando se ele atentava ou não contra os princípios e critérios da OCE no tocante a conservação dos recursos culturais. O primeiro diz respeito à apartação existente entre turistas e populações receptoras em viagens ecoturísticas. Nesse caso, o ecoturismo aproxima o homem da natureza afastando-o de seus semelhantes.

No segundo, demonstra-se a interferência dos empreendedores na produção cultural dos nativos, para torná-la mais vendável. O terceiro exemplo denuncia a edenização da natureza e a sua transformação em espetáculo, práticas culturais ocidentais essas que atentam contra a sustentabilidade na medida em que disseminam uma idéia de que há um tipo de natureza a se conservar, não dando destaque a preservação de ecossistemas que não possuam características edênicas.

Diante do reduzido número de pesquisas afetas ao assunto sustentabilidade cultural e ecoturismo na área de Turismo, procedeu-se à busca do mesmo em dissertações, teses e livros nas áreas de ciências sociais e mais restritamente em 
Antropologia Social. Por mais sucintos que fossem os artigos, eles foram valorizados, tendo em vista a raridade dos mesmos. Também houve a consulta à Internet, onde poucos sites possuíam materiais disponíveis sobre o assunto. Apesar da exigüidade de fontes e bibliografia, o trabalho foi realizado e aponta tanto distorções incompatíveis com um turismo que se pretende educativo, quanto intervenções que se pretendem humanizadoras frente aos problemas levantados.

\section{Refazendo percursos}

As problemáticas levantadas no tópico anterior têm como conseqüência: a apartação entre turistas e visitantes, a intervenção inadequada de empreendedores na execução de manifestações culturais e a espetacularização da natureza. Tudo isso está intimamente ligado às concepções de mundo trazidas pelos visitantes e empreendedores e como elas se manifestam no trato com os visitados e suas realidades. Para sanar ou mitigar os problemas levantados, procurou-se fazer intervenções que buscassem ver o fenômeno turístico como atividade multidisciplinar, que pode receber contribuições da Educação Ambiental, da Psicologia, da Filosofia e das Ciências Sociais numa plataforma holística que sempre está aberta a mais colaborações, numa tentativa de se refazer percursos, corrigindo as arestas na medida em que sejam encontradas. Antes de apresentar tais intervenções será feita uma breve digressão sobre as diferentes posturas dos estudiosos de turismo para que o trabalho cumpra melhor seu objetivo.

\subsection{Plataformas de estudo do turismo}

Nesse sentido, se faz necessário acompanhar o estudo de Jafari (1987, pp. 151-159) apud Banducci (2000, pp 21-48) que identifica quatro plataformas de estudo sobre o turismo, sendo:

- Plataforma de defesa - protagonizada por planejadores, especialistas e economistas empolgados com o crescimento da atividade. Eles não 
costumam possuir um olhar crítico aos malefícios ocasionados pela atividade, estando mais atentos aos ganhos financeiros auferidos por ela.

- Plataforma de advertência - é protagonizada por cientistas sociais, missões religiosas e setores da mídia. É bastante crítica frente aos impactos negativos realizados pela atividade tanto no âmbito cultural quanto ambiental.

- Plataforma de adaptação - questiona a possibilidade de haver turismo sem efeitos negativos para a natureza e para as populações receptoras. Daqui surge o pensamento de se haver turismo com baixo impacto ambiental.

- Plataforma de conhecimento - seus autores buscam um tratamento multidisciplinar para o turismo, saindo da esfera de se denunciar os impactos negativos da atividade, procurando vê-lo de forma holística.

É exatamente na última modalidade que o presente trabalho procura se encaixar, visto terem sido identificadas as principais distorções.

\subsection{Polaridades da natureza humana}

Com vistas a propiciar maior amplitude de entendimento faz-se uma análise filosófica do homem dentro da natureza, percebendo as suas polaridades, na tentativa de que as propostas levantadas sejam mais compatíveis com o real potencial humano e por isso se tornem mais exeqüíveis.

Na compreensão de Boff (1998) a história de cada ser humano é parte da história bio-sócio-cultural, que é capítulo de uma história cósmica. Cada homem situado na face da Terra é a síntese de uma identidade que comporta as quatro dimensões a seguir:

- Cósmica - diz respeito às partículas que o compõe e que têm a idade do universo. 
- Biológica - o corpo humano é produto de uma complexidade de fatores que fizeram com que primitivas formas de vida fossem se modificando até tornarem-se hominídeas bípedes com cérebros capazes de elaborar sínteses. O passo posterior foi o surgimento do homo sapiens que se distinguiu pela fala e pelos laços afetivos que desenvolveu, habilidades que juntas, propiciaram a cooperação entre os homens. A fala deu condições ao homem de refletir e ser consciente de si mesmo, de construir símbolos e dar significado diferenciado às coisas.

- Cultural - a cultura é realidade especifica humana. Com o auxílio da fala o homem passou a intervir na natureza ao trabalhar. Assim, criou instrumentos e aparatos tecnológicos, novas linguagens, formas de sentir, além das artes, estados-nações e a atual globalização.

- Pessoal - Cada ser humano pelo fato de ser falante possui uma descrição de si mesmo e capta o mundo de acordo com o seu repertório de experiências. Ele é único, singular, mas tem o registro do inconsciente coletivo dentro de si como marca de que também tem uma vocação para o plural, já que foi construído por pluralidades.

Essas quatro identidades fazem do ser humano um "mestiço universal", um ser híbrido, que existe de forma não linear, como tudo que está disperso no Universo. O ser humano vive sob os mesmos princípios estruturadores de toda a natureza. Estando entre a dimensão sim-bólica, que reúne coisas, que congrega o que foi lançado de diferentes pontos e a dimensão dia-bólica que lança as coisas de forma desordenada, desconectando e desunindo.

Para Boff (1998) tais dimensões são enxergadas claramente na vida do ser humano através das seguintes polarizações por este manifestas:

- Ser humano: homem e mulher - Embora homens e mulheres sejam biologicamente diferentes, ambos possuem os elementos femininos e masculinos dentro de si. A existência de elementos femininos majoritariamente no repertório da mulher e de elementos masculinos no 
repertório do homem é que causam as distorções como o patriarcalismo, a submissão da mulher, entre outras.

- Ser humano: utópico e histórico - O homem pode viver o sonho, a fantasia, a imaginação e viver também o concreto, o real, o mensurável por outro lado. Porém o real não é algo pronto e acabado, ele sofre mudanças e é delas que vêm as evoluções. A realidade está carregada de promessas, é a base para se construir o sonho. Por isso são faces de uma mesma moeda.

- Ser humano: poético e prosaico - A poesia supõe criação, idéias novas, metáforas significativas. A poesia pode levar à alegria mais suprema. $\mathrm{O}$ prosaico é o cotidiano, o trivial simples, as obrigações rotineiras. O homem precisa de ambas as potencialidades para existir saudavelmente de forma alternada ou não.

- Ser humano: ser de necessidade e criatividade - as necessidades abrem o ser humano ao mundo a fim de satisfazê-las consumindo recursos materiais e o potencial criativo coloca o homem numa esfera de também oferecer algo para seus semelhantes e para o planeta.

- Ser humano: sapiens e demens, decadente e resgatável - o ser humano não é apenas luminoso é também tenebroso. Basta ver a sua capacidade destrutiva da natureza e auto-destrutiva. A evolução humana e dos seres da natureza exige decadência e exige resgates. Qualquer homem pode tentar compensar negativamente os efeitos de sua decadência, mas pode também resgatar possibilidades na decrepitude, pois a vida deixa de ser pautada somente na garantia do vigor físico.

- Ser humano: terrenal e divino - o homem habita a Terra com todas as suas mazelas e prazeres, mas a transcendência é uma possibilidade de sair do vazio cotidiano que por vezes o invade mesmo quando vive uma atmosfera de conforto e segurança. A necessidade de se religar a poeira cósmica que o integra está sempre colocada. É a vontade de encontrar o elo perdido. O homem está no céu e na Terra ao mesmo tempo. 
Toda a exposição anterior baseada na leitura de Boff (1998), veio no sentido de possibilitar que as proposições dos autores a seguir sejam vistas a partir das polaridades do homem que refletem tanto as suas potencialidades como limitações.

\subsection{Levantando possibilidades de um turismo com sustentabilidade cultural}

As proposições estão baseadas predominantemente nos trabalhos de Bindá (1995) e Gomes (2000). Bindá (1995) teve o propósito de transcender a recorrente análise do fenômeno turístico em seus aspectos econômicos, ligados à expansão do capitalismo e usou a noção de 'sentimento de lugar', para situar uma das possíveis relações entre o turista e o lugar visitado. Gomes buscou identificar os inúmeros discursos a respeito do ecoturismo nas falas de ONG's, de agências multilaterais, do Estado e dos empreendedores da atividade. Assim, o somatório de propostas vem no sentido de transformar a viagem não em um plano de fuga das grandes cidades sem quaisquer compromissos com os locais visitados e com as culturas de seus povos, mas sim numa possibilidade de encontro que viabilize a sustentabilidade cultural.

\subsubsection{Ecoturismo e encontro}

É surpreendente que o Ecoturismo ainda que preconize o envolvimento da comunidade local, não tenha conseguido ir mais fundo no que venha a ser o tal 'envolvimento'. Apenas levar turistas às comunidades somente para comprar souvenirs e partir, logo em seguida, para um outro tour, não acrescenta nada do ponto de vista humanístico e não constrói novos paradigmas de relações entre as pessoas.

O processo civilizatório ocidental, principalmente no decorrer da Modernidade, foi responsável não só pela degradação ambiental, mas também pela degradação das relações entre os homens, manifesta inclusive no etnocentrismo exacerbado 
traduzido na incapacidade de entender que os distintos povos vivem de forma diferente, estabelecem outras maneiras de se relacionar com o tempo, com a vida, com a natureza. Possibilitar esse encontro entre visitantes e anfitriões (para além da relação comercial) é mostrar que o diferente pode ser aceitável, que as trocas entre esses dois grupos, não necessariamente, têm que repetir as tragédias que o turismo vem espalhando pelo mundo em razão de uma visão equivocada de relacionar-se com as comunidades receptoras.

A questão é muito maior que planejar a atividade turística, mas com que intuito e com que concepção de 'eco' construir o empreendimento. Certamente o ecoturismo está longe de preconizar um amor à natureza mal dissimulando o ódio aos homens, como fazem alguns setores do movimento ecológico, segundo Gauchet apud Andrade (2003). Então propiciar envolvimentos, sem artificialismos, sem teatralizações 'para turista ver' são aspirações factíveis, fazem tanto o turista quanto o nativo crescerem na troca mútua. Além disso, colaboram para o decréscimo de lodges/guetos e seu elitismo asséptico, que reafirmam o turismo tradicional. Bindá (1995, p. 46), lembra que ...os encontros sempre propiciarão a possibilidade de conceber os locais de origem dos turistas, seja através de estereótipos, das diferenças e contrastes marcantes ou pelo reconhecimento de uma humanidade compartilhada.

\subsubsection{Visão edênica e apartação da natureza defensável}

Com relação à visão edênica das paisagens, traduzida por discursos espetaculares sobre a natureza, é preciso que se diga que eles podem ser provenientes tanto da esfera cultural quanto da mercantilista. Se há a necessidade do homem contemporâneo de voltar aos Jardins do Éden (ou a qualquer outra visão de passado sem penúria) e recuperar elos perdidos, nada mais promissor ao turismo que reforçar imagens onde a fartura de vegetação, água e animais rememorem o paraíso perdido, onde a abundância era lei. O problema maior não é ufanar a natureza, até porque a natureza brasileira o vem sendo desde a 'descoberta' do Brasil em 1500, apesar de contraditoriamente os sucessivos ciclos econômicos a degradarem. Como bem revela Pádua (1987, p. 20), estudioso da história do 
ambientalismo, "temos a respeito da questão da natureza no Brasil uma tradição de dois pólos opostos esquizofrenicamente divorciados: uma celebração puramente retórica de um lado, e uma realidade de devastação impiedosa de outro".

A distorção inaceitável é ficar patente que "o discurso ecoturístico não apela por atitudes protecionistas a toda à natureza e sim de uma 'natureza particular', com certas singularidades, onde a paisagem de rara beleza cênica de alguns lugares atribui valor aos seus recursos naturais". (Gomes, 2000)

Esse tipo de postura equivocado pode ser corrigido pelas assessorias de Educação Ambiental para que não se passe aos turistas e demais envolvidos na atividade essa mentalidade. Não se espera com isso, mudar rapidamente a concepção das pessoas do trade e levar os empreendimentos para locais onde as características físicas e paisagísticas não sejam edênicas. Mas informar que a natureza se expressa em várias formas de fauna, vegetação, relevo, hidrografia, entre outros aspectos, para se evitar danos futuros aos locais não pantaneiros ou amazônicos, simplesmente por não serem nenhum nem outro. Alguém já ouviu falar de "resorts" na caatinga? Pode-se ouvir falar de turismo passando pela caatinga, mas quase nunca se exalta esse tipo de vegetação e tampouco se busca empreender onde ela existe. O que revela, como já foi dito, uma estetização da natureza entre outras suposições que não cabem aqui ser colocadas.

\subsubsection{Sentimento de Lugar}

Outra questão relevante é a relação que o turista estabelece com o lugar que visita e com os nativos. Bindá (1995) coloca em seu trabalho, que as motivações e comportamentos no turismo são importantes e que pelos mesmos, pode se incentivar aqueles que servem para determinar formas criativas de convivência com os nativos e com os espaços visitados, tentando eliminar impactos negativos. Para tanto, a autora faz uso da idéia de "sentimento de lugar" para melhor entender o turista e as diferentes características que podem assumir a sua jornada. Bindá (1995) diz que: 
“...o jogo complexo entre imaginário e experiência mostra que o local visitado participa da vida dos turistas em diversos níveis e de diversas formas, não podendo ser tomado apenas como um local sem significação própria, servindo somente como intermediário útil ao aumento do consumo, como é sugerido quando se fala em ócio burguês." (Bindá, 1995)

Bindá (1995, p. 59) afirma que o turismo pode ser pensado tanto do ponto de vista do espaço (como figura desarticulada e sem significação), quanto como a vivência de um sentimento de lugar que tem articulação e significação próprias. Traduzindo, a intimidade com um espaço pode configurá-lo, transformá-lo em lugar. Essa mudança de olhar e de sentimento conferem um "movimento dialético" entre espaço e lugar, que pode acarretar inúmeras questões apontadas por Tuan (1993), um teórico da psicologia o qual ela faz referência. O que seria esse sentimento de lugar despertado com a experiência de contato? Seria esse sentimento um meiotermo (equilíbrio) entre sentir-se enraizado no lugar e sentir-se estranho? É preciso notar que sentimento de lugar não é sentir-se do lugar, mas depende do conhecimento do mesmo.

A busca de conforto em determinada situação não pode ser imediatamente caracterizada como uma fraqueza diante dos apelos do capitalismo. Deve ser vista, segundo Bindá (1995), como um esforço para chegar a um sentimento de lugar. Nem Bindá (1995) nem Tuan (1993) especificam o tempo necessário para tal sentimento se consolidar, mas este coloca que a qualidade da experiência e sua intensidade são determinantes para vivenciá-lo. O trabalho de Bindá (1995) exemplifica atitudes bastante positivas de diferentes tipos de turistas com os locais visitados, apesar de a literatura sobre turismo na área de Ciências Sociais em geral acumular más avaliações sobre essa relação.

O mais importante é perceber que as pessoas podem desenvolver uma relação (boa ou má) com o lugar visitado, como podem apenas vê-lo como espaço descartável. 
O interessante seria, que o ecoturismo pudesse fazer da experiência da viagem por mais efêmera que se apresentasse, algo digno e carregado de alguma transcendência, oportunizando se possível viver esse sentimento de lugar, no sentido claro de provocar cuidados com a localidade visitada e simultaneamente com seus moradores.

\title{
4.3.4 Ecoturismo, empreendedores e suas trajetórias
}

De acordo com Gomes (2000):

\begin{abstract}
"Se de um lado, o movimento ambientalista trouxe um certo legado de valores, cuja mensagem conclama para a tomada de atitudes de maior solidariedade pela preservação da natureza, de outra parte o trade turístico utiliza-se disto para 'vender' uma nova viagem: a viagem ecoturística. Apesar da concepção do trade envolver o universo dos 'negócios', afinal se trata de empresas que buscam otimizar sua lucratividade, essa dimensão está em jogo sem que isto, obviamente seja pontuado no discurso. Ao contrário, explora-se um 'imaginário' onde predomina o extraordinário, o maravilhoso, o inesquecível". (Gomes, 2000, p. 81)
\end{abstract}

Há um senso-comum que afirma que o ecoturismo ainda não existe, mas que cabe às pessoas que se envolvem com o assunto fazer com que ele se construa aos poucos. Em consonância com este pensamento as universidades tentam formar a chamada 'massa crítica' para refletir sobre a teoria e prática existentes. No entanto, ambientalistas denunciam formas distorcidas com que alguns empreendedores administram seus negócios, comunidades buscam assessoria para empreender o ecoturismo dentro dos princípios e critérios assumidos pela OCE em 1994.

Uma medida importante seria identificar, nas cinco regiões do país, quem vem empreendendo o Ecoturismo se atende às questões relativas à sustentabilidade cultural. Como o Ecoturismo é muito sensível e frágil em aspectos que para outros negócios são a própria razão de existirem, como a expansão do negócio e os lucros 
crescentes; fazer aos gestores da atividade indagações que identifiquem as diferentes linhas de seus discursos contribuiria em muito para perceber como eles se autodefinem, como se distinguem um dos outros e o que esperam de sua atividade.

Conviver com esses empreendedores, lado a lado, em um ambiente de pesquisa, de observação participante, podendo perceber seus conflitos, seus obstáculos e sucessos, com certeza daria um fôlego maior aos estudos sobre essa modalidade de turismo nas áreas das Ciências Sociais, possibilitando ganhos e reconhecimento às culturas anfitriãs. Algo assim acrescentaria mais elementos ao debate sobre Ecoturismo que não só os estudos referentes aspectos econômicos, administrativos e biológicos; que de certa forma, acabam dando à atividade um cunho essencialmente tecnocrático.

Isto se justifica por ser necessária outra abordagem para o ecoturismo. No dizer de Gomes (2000) é preciso:

\begin{abstract}
"Uma compreensão baseada na ligação do homem com a natureza através da cultura e que concebe no contexto de um novo modo relacional dos seres humanos entre si, a via capaz de empreender outra interação com a natureza. Tal posição dá margem a uma nova ética da 'viagem' que, fundada em experiências mais profundas, suscita a possibilidade de diálogo entre turistas e anfitriões." (Gomes, 2000, p. 90)
\end{abstract}

Em que medidas os empreendedores (cooperativados ou não) estão sensibilizados para algo assim?

Um exemplo patente de que as Ciências Sociais têm muito a contribuir para evitar equívocos no campo de entendimento de relações entre diferentes culturas é a implantação do turismo realizada em Laguna Grande de Cuyabeno (Equador) por biólogos bastante conhecedores do Ecossistema da Reserva local, mas limitados no trato com culturas alheias. Apesar de ambicionarem respeitar as tradições dos indígenas Sionas, moradores tradicionais da localidade, de pouco adiantaram as boas intenções. Como descreve Little (1992): 
"La actividad turística lleva consigo la cuantificación de la vida cotidiana em valores monetários, de acumulación de riquezas, de obtención de productos manufaturados, etc. Estos nuevos valores, que ya están em boga dentro de la Comuna, tiendem a desplazar los valores tradicionales, entre ellos pasar largos momentos em el bosque, compartir reciprocamente los bienes de que se dispone o la confección deliberada de um produto artesanal". (Little, 1992)

Se não se tem a dimensão desses impactos sutis, não se pode percebê-los e nada se faz contra os mesmos a exemplo do que aconteceu no Equador.

Somar compreensões de diferentes campos do conhecimento é tarefa fundamental para o ecoturismo, que precisa ser além de um instrumento de proteção à natureza, um instrumento de proteção de suas populações em seus direitos inalienáveis de viver sem sofrer ataques, muitas vezes imperceptíveis.

Conhecer melhor o empreendedor, em projetos de pesquisa é tarefa de gente que quer construir um Ecoturismo com sustentabilidade ambiental, social, econômica e inclusive cultural.

\section{Considerações finais}

O ecoturismo é uma atividade que reúne possibilidades engrandecedoras para o homem contemporâneo. Neste tipo de viagem ele pode retomar o contato com a natureza e perceber sons, cores e cheiros não mais presentes em meio urbano pela degradação das condições ambientais. A viagem ecoturística também possibilita o contato com populações com costumes e valores que ainda não foram influenciados fortemente pelas formas típicas de agir e pensar das grandes cidades, fazendo com que o turista tenha outro tipo de convivência humana.

O ecoturismo é uma atividade que cresce mundialmente e é bastante promissora no Brasil em razão de sua alardeada biodiversidade e de suas belezas 
naturais evidenciadas em paisagens que vão de praias tropicais a florestas, de paisagens como a caatinga e o pantanal mato-grossense.

Todo esse contingente de potencialidades pode ser ameaçado se a sustentabilidade não for encarada como condição sem a qual ele não pode ser exercido. Em uma situação de compromisso com a sustentabilidade perdem os empreendedores de turismo, os turistas, a natureza e a população que acolhe os turistas, a natureza e a população que acolhe os visitantes e sedia os atrativos turísticos.

É importante que ao se implantar projetos de ecoturismo se veja se a sustentabilidade está sendo atendida em todas as seis dimensões propostas por Bursztyn (2000), pois somente com a existência de todas há a possibilidade de um desempenho positivo para a atividade.

O turismo de massa já forneceu suficiente material para pesquisas no campo de impactos sócio-ambientais e também culturais graças à forma equivocada em que se implantou em diferentes localidades do Brasil e do mundo. Conforme Banducci (2000), o turismo de massa é relacionado na plataforma de advertência e ao aparecimento de várias mazelas sociais como a prostituição e o tráfico de drogas, exatamente pela falta de compromisso e de planejamento de seus executores, que em geral estavam preocupados exclusivamente com os ganhos financeiros da atividade.

O ecoturismo nasceu em uma época em que se começou a questionar todos os malefícios do industrialismo e na qual novos modelos de turismo já se ocupavam de dar uma abordagem menos degradatória às viagens. O ecoturismo surge, portanto, imerso num caldo cultural que combinava dois ingredientes importantes: a luta ambientalista e a necessidade de setores da humanidade de voltarem à natureza. 
Ao mesmo tempo em que o ecoturismo surge (década de 70 , século $X X$ ) estão sendo debatidas no mundo questões relativas às formas perniciosas de desenvolvimento engendradas nos séculos XIX e XX, gestando-se no debate a idéia de desenvolvimento sustentável como alternativa aos problemas ambientais derivados do modelo criticado. Toda a conjuntura onde o ecoturismo nasceu forneceria a principio todos os elementos para que ele já começasse suas atividades sem ser alvo de polêmicas no campo da sustentabilidade cultural.

No entanto, os poucos exemplares de pesquisa na área de sustentabilidade cultural demonstram a existência de distorções graves da mesma no exercício do ecoturismo, apesar de todo o arcabouço teórico que se tem para concretizar projetos com essa dimensão de sustentabilidade.

As alternativas propostas nesse trabalho diante dos problemas evidenciados e da falta de pesquisas na área de sustentabilidade cultural e ecoturismo visaram assim:

- dar uma dimensão humanizadora à relação entre turistas e nativos;

- propiciar através da Educação Ambiental uma visão não estetizante da natureza;

- invocar no turista um sentimento de lugar ao invés da visão de visita ao espaço sem dotá-lo de qualquer significação;

- mostrar a necessidade do implemento de pesquisas qualitativas para se entender as dificuldades pelas quais passam os empreendedores em ecoturismo, a fim de sugerir-Ihes medidas compatíveis com a sustentabilidade cultural; e

- Tornar evidente a necessidade da colaboração das Ciências Sociais no planejamento do ecoturismo, para que ele não seja visto e planejado somente pelo lado comercial ou em seus aspectos biofísicos.

Há muito por se fazer em ecoturismo. Todas as 6 dimensões de sustentabilidade a serem perseguidas por empreendedores, comunidades 
receptoras,além do poder público e 0NG's exigem disposição e motivação, ambas podendo se originar de uma compreensão da polaridade humana que destrói e sabe edificar coisas maravilhosas. É preciso que se trabalhe melhor com as decepções encontradas em quaisquer projetos, principalmente naqueles que se propõem como mudanças de paradigma, porque de alguma forma eles já sinalizam querendo um caminho alternativo. Refazer os percursos se faz necessário tantas vezes na vida, refazê-los no Ecoturismo é dar mais uma chance para que cada turista possa viver o mundo com mais tolerância e mais respeito à diversidade humana e à natureza, levando essa mensagem aos que não podem viajar... 


\section{Referências bibliográficas}

ANDRADE, Maristela de. O humanismo no segundo milênio: um rápido balanço. Disponível em: <http//www.sites.uol.com.br/yesod/cadernos/edicao1/ humanismo/htm>. Acesso em: 02 mar. 2003.

AZEVEDO, Luiza Elayne. 'Lodges' no Amazonas: (eco)turismo, envolvimento comunitário e cidadania. Disponível em: <http//www.eca.usp.br/associa/ alaic/gt.15htm>. Acesso em: 02 mar. 2003.

BANDUCCI, Álvaro. Turismo e antropologia no Brasil: estudo preliminar. In: BANDUCCI, Álvaro; BARRETO, Margarida (orgs). Turismo e identidade local. Campinas: Papirus, 2001.

BEZERRA, Maria; BURSZTYN, Marcelo. Ciência e tecnologia para o desenvolvimento sustentável. Brasília: MMA, 2000. 223 p.

BINDÁ, Andréa. Viajar é mais. Brasília, 1995. 80 f. Dissertação (Mestrado em Antropologia) - Universidade de Brasília, Brasília; 1995.

BOFF, Leonardo. O despertar da águia. Petrópolis: Vozes, 1998. 174 p.

CASCINO, Fábio. Pensando a relação entre educação ambiental e ecoturismo. In: SERRANO, Célia; TURINI, Heloise. Olhares contemporâneos sobre o turismo. Campinas: Papirus, 2000. 206 p.

CEBALLOS-LASCURRAIN, H. Tourism, ecotourism and protected areas: the state of nature-based tourism around the world and guidelines for its development. Gland: IUCN, 1996. 301p.

CORIOLANO, Luzia. O ecoturismo e os hóspedes da natureza. Disponível em: <http//www.redebonja.cbj.g12.br/ielusc/turismo/iventbl/trab-coord-08>. Acesso em: 02 mar. 2003. 
DEBORD, Guy. A sociedade do espetáculo. Rio de Janeiro: Contraponto, 1997.

FIGUEIREDO, Sílvio L. Turismo e cultura: um estudo das modificações culturais no município de Soure em decorrência da exploração do turismo ecológico. In: LEMOS, Amália (org). Turismo: impactos sócio-ambientais. - 3. ed. - São Paulo: Hucitec, 2001. p. 207-222.

GOMES, Patrício. (Eco)turismo: uma (re)leitura dos discursos. Brasília, 2000. 99 f. Dissertação (Mestrado em Gestão e Política Ambiental) - Universidade de Brasília, Brasília; 2000.

HALL, Anthony. O papel das ONG's na resolução de conflitos para o desenvolvimento sustentável. In: BECKER, B.; MIRANDA, M. (orgs). A geografia política do desenvolvimento sustentável. Rio de Janeiro: UFRJ, 1997. p. 273-295

INSTITUTO BRASILEIRO DE TURISMO. Diretrizes para uma política nacional de ecoturismo. Brasília: EMBRATUR, 1994.

JAFARI, Jafar. Tourism models: the sociocultural aspects. Tourism Management, jun., pp. 151-159, 1987.

KRIPPENDORF, Jost. Sociologia do Turismo: para uma compreensão do lazer e das viagens. - 2. ed. - São Paulo: Aleph, 2001. 184 p.

LAYRARGUES, Philippe Pomier. A cortina de fumaça: ideologia e discurso empresarial verde. Disponível em: <http://www.cfch.ufrj.br/jor.pesq/ questões/pomier.html>. Acesso em: 02 mar. 2003.

LITTLE, Paul E. Cambio cultural entre los Sionas de Puerto Bolívar: ecología política del Cuyabeno. Quito: IIdis/ABYA-YAIA, 1992. p. 121-141.

LUNAS, José Roberto. Sustentável descrição e avaliação da gestão do turismo de Bonito-MS. Brasília, 1999. 106 f. Dissertação (Mestrado em Gestão Ambiental e Políticas Públicas) - Universidade de Brasília, Brasília; 2000. 
PÁDUA, José. Natureza e projeto nacional: as origens da ecologia política no Brasil. In: PÁDUA, José (org.). Ecologia e política no Brasil. Rio de Janeiro: IUPERJ, 1987. pp. 11-62.

PARESCHI, Ana Carolina Cambesis. Realismo e utopia: o trabalho de formigas em um mundo de cigarras: um estudo antropológico do discurso ambientalista. Brasília, 1997. 196 f. Dissertação (Mestrado em Antropologia Social) - Universidade de Brasília, Brasília; 1997.

PIRES, Paulo S. Ecoturismo no Brasil: uma abordagem histórico conceitual. São Paulo, 1998. 218 f. Tese (Doutorado em Geografia) - Universidade de São Paulo, São Paulo; 1998.

PROJETO OCE: Oficinas de Capacitação em Ecoturismo, 1994. Disponível em: <http/www.ecosfera.com.br>. Acesso em: 15 mar. 2003.

RIBEIRO, Gustavo Lins. Ambientalismo e desenvolvimento sustentado: nova ideologia/utopia do desenvolvimento. Revista da Antropologia, n. 34, p. 59-101, 1992.

RIBEIRO, Gustavo; BARROS, Flávia. A corrida por paisagens autênticas: turismo, meio ambiente e subjetividade no mundo contemporâneo. In: SERRANO, Célia; TURINI, Heloise. Viagens à natureza. - 3. ed. - Campinas: Papirus, 1997.

RODRIGUES, Arlete M. Desenvolvimento sustentável e atividade turística. In: SERRANO, Célia; TURINI, Heloisa. Olhares contemporâneos sobre o turismo. Campinas: Papirus, 2000. p. 171-188.

RUIZ, Álvaro. Metodologia científica: guia para eficiência nos estudos. - 4. ed. São Paulo: Atlas, 1996.

RUSCHMANN, Dóris. Turismo e planejamento sustentável: a proteção do meio ambiente. - 3. ed. - Campinas: Papirus, 1999. 199 p. 
SACHS, Ignacy. Estratégias de transição para o século XXI: desenvolvimento e meio ambiente. São Paulo: Fundap, 1993.

SALVATTI, Sérgio. Ecoturismo no Pantanal Brasileiro e Boliviano: estudo de políticas e alternativas sustentáveis. São Paulo, 2000. Dissertação (Mestrado no Programa de Pós-graduação em Integração da América Latina) - Universidade de São Paulo, São Paulo; 2000.

SERRANO, Célia. Uma introdução à discussão sobre turismo, cultura e ambiente. In: SERRANO, Célia; TURINI, Heloisa. Viagens à natureza: turismo, cultura e meio ambiente. - 3. ed. - Campinas: Papirus, 1997. p. 27-42.

SWARBROOKE, John. Turismo sustentável, turismo cultural, ecoturismo e ética. São Paulo: Aleph, 2000. 152 p.

TUAN,Yo Fu. Espaço e lugar: a perspectiva da experiência. São Paulo: Difel, 1993.

YÁZIGI, Eduardo. Turismo: uma esperança nacional. - 2 ed. rev. ampl. São Paulo: Global, 1999. 